\title{
A comparison of drugs and procedures of care in the Italian hospice and hospital settings: the final three days of life for cancer patients
}

Emily West ${ }^{*}$, Massimo Costantini ${ }^{2}$, H Roeline Pasman ${ }^{1}$, and Bregje Onwuteaka-Philipsen ${ }^{1}$ on behalf of EURO IMPACT

\begin{abstract}
Background: A palliative approach at the end of life typically involves forgoing certain drugs and procedures and starting others - weighing burden against potential benefit. An assessment of the palliative approach may be undertaken by investigating which drugs and procedures are used in the dying phase, and at what frequencies.

Methods: Drugs were classified as potentially (in)appropriate based on expert classification. Procedures were classed as therapeutic or diagnostic. 271 consecutive cancer deaths from across 16 hospital general wards and 5 hospices in Italy gathered data on drugs and procedures in the final three days of life through a standardised form. Differences between the two groups were tested using chi-square testing, and logistic regressions were performed to control for patient characteristics.
\end{abstract}

Results: $75.0 \%$ of patients in hospital received 3 or more potentially inappropriate drugs in their last three days of life, against $42.6 \%$ in hospice. Diagnostic procedures were carried out more frequently in hospital. Multivariate logistic regression showed that when data was controlled for patient characteristics, setting had a unique contribution to the differences found in use of drugs and procedures.

Conclusion: The data indicates a need for improvement in the hospital setting concerning recognising the need for palliative care, and ensuring a timely introduction of this approach.

Keywords: End-of-life, Cancer, Drugs, Therapies, Palliative

\section{Background}

Palliative care is vital to optimise both patients and caregivers' wellbeing in advanced stages of disease [1]. End of life care can be delivered in many settings, from the traditional inpatient hospice setting to care delivered at home or in hospital. The hospice model of care was initially developed to cater exclusively to the palliative approach, whereas hospital has typically been focused on curative medicine. This can particularly affect the dying phase of those cared for in hospital, as well as their families $[2,3]$. The majority of deaths in Europe occur in the hospital setting [4], and this rate is expected to rise in

\footnotetext{
* Correspondence: e.west@vumc.nl

'Department of Public and Occupational Health, EMGO + Institute for Health and Care Research - Expertise Centre for Palliative Care, VU University Medical Centre, Van der Boechorststraat 7, 1081 BT Amsterdam, The Netherlands

Full list of author information is available at the end of the article
}

light of changing demographics [5]. Thus it is important to assess the extent to which the palliative care approach is taken in different settings.

One way of looking at the palliative care approach might be to assess drugs and procedures received by patients in the dying phase. The palliative approach typically involves forgoing certain drugs and procedures, and initiating others, when burden is weighed against potential benefit in the remaining lifetime of the patient [6-8]. A change of routes of administration may also be considered in this phase, as patients' tolerance of swallowing medications, for example, lessens. However, there is no strong consensus on what drugs or procedures may be appropriate or inappropriate at the end of life. Recently a start has been made for drugs by Raijmakers et al. [9], who surveyed an international cross-section of palliative care experts and created a list of drugs deemed to be 
potentially appropriate or inappropriate for use at the end of life.

Judging the potential appropriateness of procedures is less certain, but dichotomising procedures into "therapeutic" or "diagnostic" can be helpful. Coackley and Ellershaw [10] highlight blood tests and measurement of vital signs as potentially inappropriate procedures for patients in the final days of life. This might then be extrapolated to include other procedures with diagnostic or investigative aims, rather than procedures aimed at the alleviation of symptoms. For therapeutic procedures, assessing appropriateness is more difficult still. Treatments that can be curative at another point in the disease trajectory may acquire a palliative intent - for example the use of radiotherapy to alleviate pain.

Studies comparing care given in hospices and hospital are scarce and generally do not include assessment of process of care $[11,12]$. In this study we therefore aim to assess and compare the palliative approach in hospital and hospice by looking at drugs and procedures administered during the last three days of life. The aims of this study are to investigate how often potentially appropriate and inappropriate drugs are administered in the final three days of life in hospice and in hospital; whether drugs administered in the last three days of life are given continuously, stopped or started; how often diagnostic and therapeutic procedures are used in the final three days of life in hospice and in hospital. Finally, a multivariate analysis was performed to study the association between use of drugs and procedures and setting after adjusting for patient characteristics.

\section{Methods}

\section{Design and population}

This study utilises data gathered at baseline of a clustercontrolled trial, which introduced a modified version of the Liverpool Care Pathway for the Dying Patient in 16 hospital general-medicine wards and 5 hospices across different regions in Italy [13]. At baseline, patients in general medicine wards received standard end-of-life generalist care. Data were collected through a retrospective chart review by nursing staff affiliated with the research team. Data were collected using a standardised form, completed from the patient's medical records after death. Data were gathered concerning the final three days of life, as this is the scope of the Liverpool Care Pathway as an intervention.

351 consecutive deaths in the study wards and hospices during a three-month data collection period formed the study population. Deaths were excluded if the patient was a relative of a member of staff, or if the cause of death recorded was not cancer. One patient was excluded from this analysis due to no values for drugs or procedural data being recorded. This resulted in 271 patients for whom the data on drugs and procedures were complete, 144 hospital patients and 127 hospice patients.

\section{Measurement instrument}

The registration form recorded all drugs administered and procedures (therapeutic and diagnostic) undertaken in the final three days of life. Drugs were grouped into categories organised by classification of type of drug. Data was entered as "Yes" or "No" for each category of drugs or type of procedure listed on the form for three different time points - covering the final three days of life, or part thereof, spent as an inpatient. Data on the demographic information of patients, and information concerning the final stay in hospital was also collected through the standardised form.

\section{Ethics}

The hospital cluster trial [14] received ethical approval from the Ethics Committee of the National Cancer Research Institute of Genoa (Italy) on September 14th 2009 (Reference: CCP09.001) and subsequently from the six Local Ethical Committees where the hospitals were allocated. The hospice cluster trial received ethical approval from the Ethics Committee of the National Cancer Research Institute of Genoa (Italy) on July 5th 2010 (Reference: CCP10.001) and subsequently from the four Local Ethical Committees where the hospices were allocated.

\section{Analysis}

The study population was dichotomised into hospice and hospital patients. Differences between the two groups were tested using chi-square testing, Fisher's exact test was used on cells where the expected value in cells was lower than 5. Drugs were classified as potentially inappropriate or potentially appropriate for end-of-life care based on the classification from expert opinions described by Raijmakers et al. [9]. Procedures were classed as either diagnostic or therapeutic.

To assess whether drugs that were administered were given continuously, stopped or started in the final three days of life, we selected all patients that were inpatients for at least the final three days of life (106 hospital and 107 hospice patients).

Looking at the data gathered for the three time-points, we sorted patients into the following categories per type of drug: drug not given, drug given continuously (= all three days), drug stopped in the final three days, drug started in the final three days, and a category 'other' (for rare cases with more fluctuating drug administration).

To study the association between setting and use of drugs and procedures we performed multivariate analyses after adjusting for patient characteristics. Dependent 
variables of 3 or more potentially inappropriate drugs (versus less) use of 3 or more potentially appropriate drugs (versus less), performance of one or more diagnostic procedures (versus none), and performance of two or more therapeutic procedures (versus less) were used. This was decided based on the distribution of values from initial analysis. Independent variable was setting (hospital versus hospice), and covariates were age, gender, years of education, marital status, setting the patient was referred from, primary tumour, and days as inpatient in hospital or hospice.

\section{Results}

\section{Characteristics of study patients}

Of patients included in the study, the mean age was similar between settings (76 in hospital and 74 in hospice) and length of stay showed little difference, with a stay of over 7 days the case for over $48 \%$ of patients in either setting. Data showed significant differences between hospice and hospital populations in terms of demographic characteristics $-69.4 \%$ of patients in hospital were male compared to $55.1 \%$ in hospice, and patients in hospital were more often found to be married than their counterparts in hospice (67.4\% versus 51.8\%). Education level also differed significantly between settings with almost double the number of patients in hospice having completed over 9 years of education when compared with hospital (36.4\% versus 18.4\%). In hospice, more patients were referred from home (87.8\% versus $40.2 \%)$ than in hospital (Table 1).

\section{Use of potentially inappropriate and appropriate drugs )}

The mean and median number of all drugs received in hospice was 5.95 and 6.00 respectively. In hospital this was 5.13 and 5.00. Table 2 shows that in hospital more potentially inappropriate drugs were used than in hospice: $75.0 \%$ of patients in hospital received 3 or more potentially inappropriate drugs in their last three days of life as opposed to $42.6 \%$ in hospice. A significant difference was observed for five of the potentially inappropriate classes of drugs: antibiotics $(61.8 \%$ versus $14.2 \%$; $\mathrm{P}=.000)$, anticoagulants (50.7\% versus $33.9 \% ; \mathrm{P}=.020)$, supplements (36.1\% versus $9.4 \% ; \mathrm{P}=.000)$, antihypertensives $(26.9 \%$ versus $9.4 \% ; \mathrm{P}=.001)$, and dopamine $(6.2 \%$

Table 1 Characteristics of patients in hospital and hospice

\begin{tabular}{|c|c|c|c|c|c|c|}
\hline & & \multicolumn{2}{|c|}{ Hospital N=144 } & \multicolumn{2}{|c|}{ Hospice $N=127$} & \multirow[t]{2}{*}{ P-value } \\
\hline & & n. & $\%$ & n. & $\%$ & \\
\hline Age & (mean, range) & 76 & $(46-97)$ & 74 & $(43-96)$ & .324 \\
\hline \multirow[t]{2}{*}{ Gender } & Male & 100 & 69.4 & 70 & 55.1 & \\
\hline & Female & 44 & 30.6 & 57 & 44.9 & $.017^{*}$ \\
\hline \multirow[t]{4}{*}{ Education (years) } & $9-13$ & 21 & 18.4 & 35 & 36.4 & \\
\hline & $6-8$ & 26 & 22.8 & 23 & 24.0 & \\
\hline & $0-5$ & 67 & 58.8 & 38 & 39.6 & .006 \\
\hline & Unknown & 30 & & 31 & & \\
\hline \multirow[t]{3}{*}{ Marital status } & Single & 42 & 32.6 & 55 & 48.2 & \\
\hline & Married & 87 & 67.4 & 59 & 51.8 & $.018^{*}$ \\
\hline & Unknown & 15 & & 13 & & \\
\hline \multirow[t]{4}{*}{ Referred from } & Home & 122 & 87.8 & 51 & 40.2 & \\
\hline & Nursing home & 7 & 5.0 & 8 & 6.3 & \\
\hline & Hospital & 10 & 6.9 & 68 & 53.5 & .000 \\
\hline & Unknown & 5 & & - & & \\
\hline \multirow[t]{6}{*}{ Primary tumour } & Digestive system & 44 & 30.6 & 41 & 32.3 & \\
\hline & Respiratory system & 40 & 27.8 & 30 & 23.6 & \\
\hline & Genitourinary system & 14 & 9.7 & 24 & 18.9 & \\
\hline & Haematological & 27 & 18.8 & 7 & 5.5 & \\
\hline & Breast & 8 & 5.6 & 5 & 3.9 & \\
\hline & Others & 11 & 7.6 & 20 & 15.7 & .003 \\
\hline \multirow[t]{3}{*}{ Days as inpatient } & $0-3$ & 37 & 25.7 & 20 & 15.7 & \\
\hline & $4-7$ & 37 & 25.7 & 29 & 22.8 & \\
\hline & $7+$ & 70 & 48.6 & 78 & 61.4 & .066 \\
\hline
\end{tabular}

$\mathrm{P}$ values marked ${ }^{*}$ are results of Fisher's Exact Test (2-sided). 
Table 2 Frequency of potentially inappropriate and appropriate drugs delivered in the final three days of life in hospital and in hospice

\begin{tabular}{|c|c|c|c|c|c|c|}
\hline & & \multicolumn{2}{|c|}{ Hospital $N=144$} & \multicolumn{2}{|c|}{ Hospice $N=127$} & \multirow[t]{2}{*}{ P-value } \\
\hline & & n. & $\%$ & n. & $\%$ & \\
\hline \multicolumn{7}{|l|}{ Potentially inappropriate drugs* } \\
\hline Antiulcer Drugs & & 104 & 72.2 & 82 & 64.6 & .398 \\
\hline Antibiotics & & 89 & 61.8 & 18 & 14.2 & .000 \\
\hline Steroids & & 82 & 56.9 & 79 & 62.2 & .668 \\
\hline Anticoagulents & & 73 & 50.7 & 43 & 33.9 & .020 \\
\hline Supplements & & 52 & 36.1 & 12 & 9.4 & .000 \\
\hline Antihypertensives & & 39 & 26.9 & 12 & 9.4 & .001 \\
\hline Antiarryhthmics & & 25 & 17.4 & 10 & 7.9 & .067 \\
\hline Replacement Hormones & & 22 & 15.3 & 11 & 8.7 & .251 \\
\hline Vasodilator Drugs & & 16 & 11.1 & 5 & 3.9 & .088 \\
\hline Dopamine & & 9 & 6.2 & 0 & 0 & .016 \\
\hline \multirow[t]{4}{*}{ Number of inappropriate drugs } & 0 & 8 & 5.6 & 20 & 15.9 & \\
\hline & $1-2$ & 28 & 19.6 & 53 & 42.1 & \\
\hline & $3-4$ & 66 & 45.8 & 46 & 36.5 & \\
\hline & $5+$ & 41 & 28.7 & 7 & 5.6 & .000 \\
\hline \multicolumn{7}{|l|}{ Potentially appropriate drugs } \\
\hline Opioids & & 97 & 66.9 & 112 & 88.2 & .000 \\
\hline Drugs for NauseaNomiting & & 22 & 15.3 & 27 & 21.3 & .438 \\
\hline Haloperidol & & 17 & 11.8 & 81 & 63.8 & .000 \\
\hline Midazolam & & 8 & 5.6 & 91 & 71.7 & .000 \\
\hline Drugs for pulmonary secretions & & 6 & 4.2 & 60 & 47.2 & .000 \\
\hline \multirow[t]{4}{*}{ Number of appropriate drugs } & 0 & 45 & 31.3 & 8 & 6.3 & \\
\hline & $1-2$ & 98 & 68.5 & 111 & 88.1 & \\
\hline & $3-4$ & - & - & 7 & 5.6 & \\
\hline & $5+$ & - & - & - & - & .000 \\
\hline
\end{tabular}

*Use of bisphosphonates was also assessed, but no positive values were returned from either setting.

versus none; $\mathrm{P}=.016)$. In contrast, potentially appropriate drugs were used less in hospital than in hospice: $68.5 \%$ of patients in hospital received $1-2$ potentially appropriate drugs as opposed to $88.1 \%$ in hospice. A significant difference was seen in of 4 of the 5 potentially appropriate drugs: Opioids $(66.9 \%$ versus $88.2 \%$; $\mathrm{P}=.000)$, haloperidol $(11.8 \%$ versus $63.8 \%$; $\mathrm{P}=0.000)$, midazolam (5.6\% versus $71.7 \% ; \mathrm{P}=0.000$ ), and drugs for pulmonary secretions (4.2\% and 47.2\%; $\mathrm{P}=0.000)$ (Table 2).

\section{Pattern of drug use in the last three days}

Of potentially inappropriate drugs, many were used more widely in general in the hospital than hospice setting, with less patients failing under the category of "Drug not given". Hospital patients showed a much greater incidence of having certain potentially inappropriate drugs stopped within the final three days of life than hospice patients - including antibiotics (24.5\% versus $8.4 \%)$, antihypertensives (17.9\% versus $8.4 \%)$, anticoagulants $(37.7 \%$ versus $19.6 \%)$, and supplements (28.3\% versus $7.5 \%)$. Conversely, potentially appropriate drugs were found to be more likely to be given continuously in the hospice than hospital setting. Opioids were delivered continuously at over twice the rate in hospice than in hospital $(65.4 \%$ versus $28.3 \%$ ). These drugs were less frequently started in the final three days in hospice $(12.1 \%$ and $7.5 \%)$ than in hospital $(20.8 \%$ and $13.3 \%)$. In contrast, midazolam, haloperidol, and drugs for pulmonary secretions were more frequently started in the final three days in hospice $(17.8 \%$, $7.5 \%$ and $14.0 \%)$ than in hospital (3.8\%, $1.9 \%$ and $1.9 \%)$ (Table 3).

Procedures undertaken in final three days of life

The mean and median number of all procedures received in hospice was 1.74 and 1.00 respectively. In hospital this was 2.58 and 2.00 . Table 4 shows that diagnostic procedures were carried out more frequently in the hospital than hospice setting: $38.9 \%$ of hospital patients had one or 
Table 3 Longitudinal drug data for patients who stayed over 3 days in hospital and in hospice

\begin{tabular}{|c|c|c|c|c|c|}
\hline \multirow[b]{2}{*}{ Potentially inappropriate drugs } & \multicolumn{2}{|c|}{ Hospital N = 106} & \multicolumn{2}{|c|}{ Hospice $\mathrm{N}=107$} & \multirow[t]{2}{*}{ P-value } \\
\hline & n. & $\%$ & n. & $\%$ & \\
\hline \multicolumn{6}{|l|}{ Supplements } \\
\hline Drug not given & 59 & 55.7 & 97 & 90.7 & \\
\hline Drug given continuously & 14 & 13.2 & 1 & 0.9 & \\
\hline Drug stopped in final three days & 30 & 28.3 & 8 & 7.5 & \\
\hline Drug started in final three days & 1 & 0.9 & 1 & 0.9 & \\
\hline Other & 2 & 1.9 & - & - & .000 \\
\hline \multicolumn{6}{|l|}{ Replacement hormones } \\
\hline Drug not given & 87 & 82.1 & 94 & 87.9 & \\
\hline Drug given continuously & 12 & 11.3 & 1 & 0.9 & \\
\hline Drug stopped in final three days & 7 & 6.6 & 10 & 9.3 & \\
\hline Drug started in final three days & - & - & - & - & \\
\hline Other & - & - & 2 & 1.9 & .007 \\
\hline \multicolumn{6}{|l|}{ Antiulcer Drugs } \\
\hline Drug not given & 25 & 23.6 & 37 & 34.6 & \\
\hline Drug given continuously & 27 & 25.5 & 23 & 21.5 & \\
\hline Drug stopped in final three days & 50 & 47.2 & 41 & 38.3 & \\
\hline Drug started in final three days & 1 & 0.9 & 2 & 1.9 & \\
\hline Other & 3 & 2.8 & 4 & 3.7 & .405 \\
\hline \multicolumn{6}{|l|}{ Anticoagulents } \\
\hline Drug not given & 45 & 42.5 & 73 & 68.2 & \\
\hline Drug given continuously & 14 & 13.2 & 6 & 5.6 & \\
\hline Drug stopped in final three days & 40 & 37.7 & 21 & 19.6 & \\
\hline Drug started in final three days & 3 & 2.8 & - & - & \\
\hline Other & 4 & 3.8 & 7 & 6.5 & .001 \\
\hline \multicolumn{6}{|l|}{ Antihypertensives } \\
\hline Drug not given & 71 & 67.0 & 97 & 90.7 & \\
\hline Drug given continuously & 10 & 9.4 & - & - & \\
\hline Drug stopped in final three days & 19 & 17.9 & 9 & 8.4 & \\
\hline Drug started in final three days & 2 & 1.9 & 1 & 0.9 & \\
\hline Other & 4 & 3.8 & - & - & .000 \\
\hline \multicolumn{6}{|l|}{ Antiarryhthmics } \\
\hline Drug not given & 86 & 81.1 & 97 & 90.7 & \\
\hline Drug given continuously & 8 & 7.5 & 3 & 2.8 & \\
\hline Drug stopped in final three days & 10 & 9.4 & 6 & 5.6 & \\
\hline Drug started in final three days & 1 & 0.9 & 1 & 0.9 & \\
\hline Other & 1 & 0.9 & - & - & .295 \\
\hline \multicolumn{6}{|l|}{ Antibiotics } \\
\hline Drug not given & 41 & 38.7 & 90 & 84.1 & \\
\hline Drug given continuously & 25 & 23.6 & 5 & 4.7 & \\
\hline Drug stopped in final three days & 36 & 24.5 & 9 & 8.4 & \\
\hline Drug started in final three days & 1 & 0.9 & 3 & 2.8 & \\
\hline Other & 3 & 2.8 & - & - & .000 \\
\hline
\end{tabular}


Table 3 Longitudinal drug data for patients who stayed over 3 days in hospital and in hospice (Continued)

Steroids

Drug not given

44

Drug given continuously

Drug stopped in final three days

Drug started in final three days

Other

Vasodilator Drugs

Drug not given

Drug given continuously

Drug stopped in final three days

Drug started in final three days

Other

Dopamine

Drug not given

Drug given continuously

Drug stopped in final three days

Drug started in final three days

Other

Potentially appropriate drugs

Opioids

Drug not given

Drug given continuously

Drug stopped in final three days

Drug started in final three days

Other

Midazolam

Drug not given

Drug given continuously

Drug stopped in final three days

Drug started in final three days

Other

Haloperidol

Drug not given

Drug given continuously

Drug stopped in final three days

Drug started in final three days

Other

Drugs for pulmonary secretions

Drug not given

102

Drug given continuously

Drug stopped in final three days

Drug started in final three days

Other

Drugs for Nausea/Nomiting

Drug not given
36.4

20.6

32.7

2.8
7.5

95.3

1.9

2.8 
Table 3 Longitudinal drug data for patients who stayed over 3 days in hospital and in hospice (Continued)

\begin{tabular}{lllll}
\hline Drug given continuously & 4 & 3.8 & 5 & 4.7 \\
Drug stopped in final three days & 8 & 7.5 & 17 & 15.9 \\
Drug started in final three days & 4 & 3.8 & 2 & 1.9 \\
Other & - & - & 2 & 1.9 \\
\hline
\end{tabular}

more diagnostic procedures in their last days of life against $15.0 \%$ of hospice patients. The largest difference between hospital and hospice was found for analysis of arterial blood gases (16.7\% versus $0.8 \%$ ) and x-rays (13.9\% versus $0.0 \%)$. No significant difference was found for the number of therapeutic procedures delivered between hospital and hospice setting - $84.7 \%$ of hospital patients and $85.0 \%$ of hospice patients received one or more therapeutic procedures. For two therapeutic procedures - oxygen $(63.2 \%$ versus $40.2 \%)$ and transfusion (11.1\% and $0.0 \%)$ - it was found that they were delivered more in hospital than in hospice (Table 4).

Table 4 Frequency of diagnostic and therapeutic procedures delivered in the final three days of life in hospital and in hospice

Hospital $\mathrm{N}=144$

\section{Procedures}

Diagnostic procedures*

ECG

Arterial blood gases

X-ray

Ultrasound

CT scan

Biopsy

Number of diagnostic procedures

$0 \quad 88$

$1-2 \quad 47$

$3-5 \quad 9$

$5+$

Therapeutic procedures**

Oxygen

1 *Vesical Catheterisation

Artificial Hydration (or CVC)

Bronchial Aspiration

Transfusion

Enema

CPR

Chemotherapy

Drainage

Non-Invasive Ventilation

Radiotherapy

Removal of faecal impaction

Intubation

Number of therapeutic procedures

$$
-
$$

\section{5}

16.7

13.9

6.3

6.3

1.4

61.1

32.6

6.3
Hospice $\mathrm{N}=127$ P-value

\begin{tabular}{|c|c|c|c|c|}
\hline 91 & 63.2 & 51 & 40.2 & $<.001^{*}$ \\
\hline 79 & 54.9 & 76 & 59.8 & $.461^{*}$ \\
\hline 22 & 15.3 & 31 & 24.4 & $.066^{*}$ \\
\hline 17 & 11.8 & 23 & 18.1 & $.171^{*}$ \\
\hline 16 & 11.1 & 0 & 0 & $<.001^{*}$ \\
\hline 15 & 10.4 & 10 & 7.9 & $.532^{*}$ \\
\hline 4 & 2.8 & 0 & 0 & $.125^{*}$ \\
\hline 4 & 2.8 & 0 & 0 & .150 \\
\hline 3 & 2.1 & 3 & 2.4 & $1^{*}$ \\
\hline 2 & 1.4 & 0 & 0 & $.500^{*}$ \\
\hline 1 & 0.7 & 0 & 0 & $1^{*}$ \\
\hline- & - & 2 & 1.6 & $.219^{*}$ \\
\hline- & - & 1 & 0.8 & $.469^{*}$ \\
\hline 22 & 15.3 & 19 & 15.0 & \\
\hline 84 & 58.3 & 82 & 64.6 & \\
\hline 37 & 25.7 & 25 & 19.7 & \\
\hline $5+$ & 0.7 & 1 & 0.8 & .681 \\
\hline
\end{tabular}

*Use of MRI was also assessed, but no positive values were returned from either setting.

**Dialysis, invasive ventilation, tracheotomy and peritoneal catheterisation were also assessed, but no positive values were returned from either setting.

$P$ values marked * are results of Fisher's Exact Test (2-sided). 


\section{Unique contribution of setting to use of drugs and procedures}

Multivariate logistic regression analysis showed that when data was controlled for all patient characteristics described in Table 1, setting had a unique contribution to the differences found in drugs used and procedures delivered. In the hospital setting, patients had a higher probability of receiving three or more inappropriate drugs $(\mathrm{OR}=3.52$, $95 \% \mathrm{CI}=1.83-6.78$ ), and were less likely to receive three or more appropriate drugs $(\mathrm{OR}=.08,95 \% \mathrm{CI}=.04-.18)$ than in the hospice setting. Furthermore, patients in hospital were times more likely to undergo one or more diagnostic procedure $(\mathrm{OR}=3.50,95 \% \mathrm{CI}=1.15-7.88)$ than hospice patients. There was no difference in chance on receiving two or more therapeutic procedures between hospital and hospice patients $(\mathrm{OR}=1.46,95 \% \mathrm{CI}=$ $.78-2.74)$.

\section{Discussion}

The analysis showed that, when looking at administration of potentially inappropriate and appropriate drugs and use of diagnostic and therapeutic procedures, hospices use a more palliative approach than hospitals in patients' last three days of life, and less administration of potentially inappropriate drugs. A higher proportion of opioids are started in these final three days. Hospital patients more often receive potentially inappropriate drugs, such as anticoagulants and antibiotics, and less often receive potentially appropriate drugs, such as opioids, haloperidol and drugs for pulmonary secretions than hospice patients. They also receive more diagnostic procedures such as analysis of arterial blood gases and x-rays. Analyses controlling for differences in patient characteristics in hospital and hospice show that setting has a unique contribution to the differences found.

\section{Strengths and limitations}

The study data was populated through clinical chart review, translated into a standardised form. This is an efficient and reliable means of research, as it relies on data that exists as part of the patient's care continuum. The study, however, has limitations. The categorisation of drugs into "potentially appropriate" and "potentially inappropriate" is based on one survey of experts, so cannot be taken to represent a wider consensus. Furthermore, whether a drug is appropriate or inappropriate also depends on the situation of the patient. Similarly, the separation of procedures into "diagnostic" and "therapeutic" cannot be taken to infer an inherent validity of the use of any given procedure. As treatment options and symptoms differ so much between conditions there cannot be a proscriptive range of treatments that are deemed to always be "suitable" or "unsuitable" in the end of life setting. However, to use an analogy with quality indicators, one could consider that a low percentage of potentially inappropriate drugs and diagnostic procedures is a preferable outcome. Such indicators are currently used in wider hospital or system research, and may indicate a norm of drug use considered good, for example [14]. Such norms do not exist yet for drugs and procedures in the last days of life. The concept of the dying phase is also the subject of much debate, though recent research [15] highlights the presence of certain physical signs present within the final three days of life for cancer patients. Finally, while the design allowed us to control for several patient characteristics in analysing the contribution of setting to use of drugs and procedures, it is possible that there are other patient characteristics that interfere in the found relationship.

\section{Comparison with existing literature}

Background research for the formulation of this paper highlighted a paucity of existing studies that assessed process of care as received by dying patients. Currently very little data exists to compare the use of drugs and procedures delivered at the end of life in different settings to provide a measure of process of care. Previous papers have explored assessments of quality of life and caregiver distress between different settings, but explicit data recording process of care remains scarce $[16,17]$.

\section{The difficult transition to palliation in hospitals}

Results show that hospitals more often use potentially inappropriate drugs within the final three days of life than hospices, but often stop these during this period. This may indicate that the palliative approach is recognised as appropriate, and that this is acted on, but at a much later stage than in the hospice setting. Earle et al. [18] found an increase in aggressiveness of treatment received by patients in an acute hospital setting over three years. This can be exacerbated by developments in technology and pharmacology, which encourage physicians to go to greater lengths to try to "save" a patient, and a prevailing culture that sees death in the acute setting as a failure of medical staff [8], potentially affecting the point at which the palliative approach is begun.

\section{The patient perspective on appropriate care}

The consideration of burden of care is important in making decisions at the end of life, and procedures must be assessed with the holistic needs of the patient in mind not only medical aspects of care, but also psychosocial and spiritual needs [19]. Fried [20], in a study of elderly patients making end-of-life treatment decisions, found that burden of treatments was weighed by patients against anticipated outcomes and a more marginal outcome lead to less willingness to consider a treatment. This must be considered in the case of potentially inappropriate drugs 
and procedures, where the perceived benefit of a drug or procedure to the patient or family may be greater than the burden of administration. Thus a strictly scientific classification of appropriateness may be at odds with patient experience of such drugs and procedures. The same is true for potentially appropriate drugs and procedures - for instance, it is known that some patients are reluctant to use opioids because of fears of becoming drowsy and unaware at the end of life [21]. Solid information that allows patients to weigh benefits against burdens, and make informed and shared decisions alongside medical staff should be made available.

\section{Conclusion}

The data indicates a need for improvement in the hospital setting concerning recognising the need for palliative care, and ensuring a timely transition to this for the patient. It is not possible to say on an abstract level that any one type of drug or procedure is appropriate or inappropriate for any given patient, but the observation of data on this scale suggests that the process of care is not fitting the palliative needs of patients. Pathways such as the Liverpool Care Pathway have made steps towards introducing such a philosophy into hospital care, but a stronger evidence base must be built before introducing such initiatives in a widespread way $[22,12]$.

\section{Competing interests}

The authors declare that they have no competing interests.

\section{Authors' contributions}

EW drafted the paper and performed the main statistical analyses. MC provided extensive background expertise. HRWP provided methodological guidance and technical knowledge. BOP guided the form and format of the study and writing up. All authors read and approved the final manuscript.

\section{Authors' information}

Collaborators

Van den Block Lieve ${ }^{a}$, De Groote Zeger ${ }^{a}$, Brearley Sarah ${ }^{e}$, Caraceni Augusto ${ }^{\text {g, }}$, Cohen Joachim ${ }^{a}$, Francke Anneke ${ }^{b}$, Harding Richard ${ }^{c, d}$, Higginson Irene $J^{c, d}$, Kaasa Stein ${ }^{f}$, Linden Karen ${ }^{k}$, Miccinesi Guido i, Onwuteaka-Philipsen Bregje ${ }^{\text {', }}$ Pardon Koen ${ }^{a}$, Pasman Roeline ${ }^{b}$, Pautex Sophie ${ }^{j}$, Payne Sheila ${ }^{e}$, Deliens Luc a,b

\section{Acknowledgements}

EURO IMPACT, European Intersectorial and Multidisciplinary Palliative Care Research Training, is funded by the European Union Seventh Framework Programme (FP7/2007-2013, under grant agreement $n^{\circ}$ [264697]). EURO IMPACT aims to develop a multidisciplinary, multi-professional and intersectorial educational and research training framework for palliative care research in Europe. EURO IMPACT is coordinated by Prof Luc Deliens and Prof Lieve Van den Block of the End-of-Life Care Research Group, Ghent University \& Vrije Universiteit Brussel, Brussels, Belgium ${ }^{\text {a }}$. Other partners are: VU University Medical Center, EMGO Institute for health and care research, Amsterdam, the Netherlands ' ${ }^{\text {; }}$ King's College London, Cicely Saunders Institute, London ', Cicely Saunders International, London ' , and International Observatory on End-of-Life Care, Lancaster University, Lancaster, United Kingdom ${ }^{e}$; Norwegian University of Science and Technology ${ }^{\mathrm{f}}$, and EAPC Research Network ${ }^{9}$,Trondheim, Norway; Fondazione IRCCS Istituto Nazionale dei Tumori, Milan, Italy ${ }^{h}$, and Cancer Research and Prevention Institute, Florence, Italy i; EUGMS European Union Geriatric Medicine Society, Geneva, Switzerland j; Springer Science and Business Media, Houten, the Netherlands ${ }^{k}$.

\section{Author details}

${ }^{1}$ Department of Public and Occupational Health, EMGO + Institute for Health and Care Research - Expertise Centre for Palliative Care, VU University Medical Centre, Van der Boechorststraat 7, 1081 BT Amsterdam, The Netherlands. ${ }^{2}$ Palliative Care Unit, IRCCS Arcispedale S. Maria Nuova, Reggio Emilia, Italy.

Received: 12 June 2014 Accepted: 6 October 2014

Published online: 25 October 2014

\section{References}

1. Improving Supportive and Palliative Care for Adults with Cancer. Available at: http://www.nice.org.uk/guidance/csgsp/evidence/supportiveandpalliative-care-the-manual-2. Accessed April 14, 2014.

2. Higginson IJ, Costantini M: Dying with cancer, living well with advanced cancer. Eur J Cancer 2008, 44(10):1414-1424. doi:10.1016/j.ejca.2008.02.024.

3. Teno JM, Clarridge BR, Casey V, Welch LC, Wetle T, Shield R, Mor V: Family perspectives on end-of-life care at the last place of care. JAMA 2004, 291(1):88-93. doi:10.1001/jama.291.1.88.

4. Houttekier D, Cohen J, Van den Block L, Bossuyt N, Deliens L: Involvement of palliative care services strongly predicts place of death in Belgium. J Palliat Med 2010, 13(12):1461-1468. doi:10.1089/jpm.2010.0279.

5. Gomes B, Higginson IJ: Where people die (1974-2030): past trends, future projections and implications for care. Palliat Med 2008, 22(1):33-41. doi:10.1177/0269216307084606.

6. The Management of Terminal Malignant Disease. 1985. Available at: http:// books.google.nl/books/about/The_Management_of_Terminal_Malignant_ Dis.html?id=9fFHHAAACAAJ\&redir_esc=y. Accessed April 14, 2014.

7. Coackley A, Ellershaw J: The terminal phase. Medicine (Baltimore) 2008, 36(2):105-108. doi:10.1016/j.mpmed.2007.11.013.

8. Chapman L, Ellershaw J: Care in the last hours and days of life. Medicine (Baltimore) 2011, 39(11):674-677. doi:10.1016/j.mpmed.2011.08.001.

9. Raijmakers NJH, van Zuylen L, Furst CJ, Beccaro M, Maiorana L, Pilastri P, Rossi C, Flego G, van der Heide A, Costantini M: Variation in medication use in cancer patients at the end of life: a cross-sectional analysis. Support Care Cancer 2013, 21(4):1003-1011. doi:10.1007/s00520-012-1619-0.

10. Olsen ML, Swetz KM, Mueller PS: Ethical decision making with end-oflife care: palliative sedation and withholding or withdrawing lifesustaining treatments. Mayo Clin Proc 2010, 85(10):949-954. doi:10.4065/mcp.2010.0201.

11. Veerbeek L, van Zuylen L, Gambles M, Swart SJ, van der Heide A, van der Rijt CC, Ellershaw JE: Audit of the Liverpool care pathway for the dying patient in a dutch cancer hospital. J Palliat Care 2006, 22(4):305-308. Available at: http://www.ncbi.nlm.nih.gov/pubmed/17263060. Accessed April 14, 2014.

12. Di Leo S, Bono L, Romoli V, West E, Ambrosio R, Gallucci M, Pilastri P, Ciura PL, Morino P, Piazza M, Valenti D, Franceschini C, Costantini M: Implementation of the Liverpool care pathway (LCP) for the dying patient in the inpatient hospice setting: development and preliminary assessment of the Italian LCP program. Am J Hosp Palliat Care 2014, 31(1):61-68. doi:10.1177/1049909113482355.

13. Costantini M, Ottonelli S, Canavacci L, Pellegrini F, Beccaro M: The effectiveness of the Liverpool care pathway in improving end of life care for dying cancer patients in hospital. A cluster randomised trial. BMC Health Serv Res 2011, 11(1):13. doi:10.1186/1472-6963-11-13.

14. Ballard DJ: Indicators to improve clinical quality across an integrated health care system. Int J Qual Heal Care 2003, 15(90001):13i-23i. doi:10.1093/intahc/mzg080

15. Hui D, Dos Santos R, Chisholm G, Bansal S, Silva TB, Kilgore K, Crovador CS, Yu X, Swartz MD, Perez-Cruz PE, Leite Rde A, Nascimento MS, Reddy S, Seriaco F, Yennu S, Paiva CE, Dev R, Hall S, Fajardo J, Bruera E: Clinical signs of impending death in cancer patients. Oncologist 2014, 19(6):681-687. doi:10.1634/theoncologist.2013-0457. Epub 2014 Apr 23.

16. Gomes B, Calanzani N, Curiale V, McCrone P, Higginson IJ: Effectiveness and cost-effectiveness of home palliative care services for adults with advanced illness and their caregivers. Cochrane Database Syst Rev 2013, 6:CD007760. doi:10.1002/14651858.CD007760.pub2.

17. Higginson IJ, Evans CJ: What is the evidence that palliative care teams improve outcomes for cancer patients and their families? Cancer J 2010, 16(5):423-435. 
18. Earle CC, Neville BA, Landrum MB, Ayanian JZ, Block SD, Weeks JC: Trends in the aggressiveness of cancer care near the end of life. J Clin Oncol 2004, 22(2):315-321. doi:10.1200/JCO.2004.08.136.

19. Bausewein C, Booth S, Gysels M, Kühnbach R, Haberland B, Higginson IJ: Understanding breathlessness: cross-sectional comparison of symptom burden and palliative care needs in chronic obstructive pulmonary disease and cancer. J Palliat Med 2010, 13(9):1109-1118. doi:10.1089/ jpm.2010.0068.

20. Goldstein NE, Concato J, Fried TR, KasI SV, Johnson-Hurzeler R, Bradley EH: Factors associated with caregiver burden among caregivers of terminally ill patients with cancer. J Palliat Care 2004, 20(1):38-43. Available at: http:// europepmc.org/abstract/MED/15132075/reload=0. Accessed April 14, 2014.

21. Fineberg IC, Wenger NS, Brown-Saltzman K: Unrestricted opiate administration for pain and suffering at the end of life: knowledge and attitudes as barriers to care. J Palliat Med 2006, 9(4):873-883. doi:10.1089/ jpm.2006.9.873.

22. Ellershaw J, Foster A: Developing an integrated care pathway for the dying patient. Eur 1997. Available at: http://scholar.google.co.uk/scholar? lookup $=0 \& q=$ Developing + an + integrated + care + pathway+for+the + dying+patient\&hl=en\&as_sdt=0,5. Accessed April 14, 2014.

doi:10.1186/s12913-014-0496-2

Cite this article as: West et al.: A comparison of drugs and procedures of care in the Italian hospice and hospital settings: the final three days of life for cancer patients. BMC Health Services Research 2014 14:496.

\section{Submit your next manuscript to BioMed Central and take full advantage of:}

- Convenient online submission

- Thorough peer review

- No space constraints or color figure charges

- Immediate publication on acceptance

- Inclusion in PubMed, CAS, Scopus and Google Scholar

- Research which is freely available for redistribution 